\title{
NOTA ACLARATORIA SOBRE LAS HOJAS DE VALERIANA VAGINATA (VALERIANACEAE)
}

Valeriana vaginata HBK. ( $=V$. denudata Benth.) es una especie no del todo rara, conocida de la parte sur de la Altiplanicie Mexicana y del Eje Volcánico Transversal, donde habita principalmente en bosques abiertos de pino y de encino, a menudo en claros en medio de tales bosques, mostrando preferencia por un sustrato, al menos moderadamente, rocoso.

La planta en cuestión es una geófita provista de raíz tuberosa, frecuentemente hasta de $7 \mathrm{~cm}$ de diámetro; florece y fructifica en abril y mayo (a veces hasta julio), a finales de la época de sequía. El epíteto vaginata alude a las "hojas", que se observan como estructuras envainantes en la base, reducidas en tamaño y de color pálido (fig. 1). Meyer, quien publicó la monografía del grupo (Ann. Mo. Bot. Gard. 38: 377-503. 1951), comenta al respecto (p. 454) que "the vaginate leaves are the most reduced of any North American species of Valeriana".

En el transcurso de la preparación de la Flora Fanerogámica del Valle de México, en su parte relativa al género Valeriana, se encontraron en los herbarios consultados varios ejemplares con rasgos que coinciden con los descritos para V. vaginata. Se hallaron asimismo unos pocos especímenes sin flor ni fruto, correspondientes a plantas colectadas durante la época lluviosa del año, con partes subterráneas similares a las de $V$. vaginata y con hojas todas radicales, verdes y de forma característica (fig. 2), que no corresponde a las descritas para ninguna de las especies conocidas de Valeriana de México.

Dados estos antecedentse, así como el hecho de que una de las localidades de hallazgo de la planta estéril coincide con la zona en que se ha colectado también $V$. vaginata, se sospechó que pudiera tratarse de formas estacionales de la misma especie. Con el objeto de comprobar tal hipótesis, cerca del Volcán Xitle (al NW del poblado de Ajusco, Distrito Federal) se marcaron varios individuos de V. vaginata mientras estaban en flor y también se trajeron dos plantas vivas para observar su desarrollo en la ciudad de México. Tanto los individuos marcados en el campo, como los cultivados en maceta, desarrollaron hojas similares a las previamente observadas en los ejemplares de herbario estériles.

FIG. 1 Y 2

A la luz de lo anterior cabe concluir que las estructuras descritas en la literatura como hojas de $V$. vaginata en realidad representan brácteas del escapo y de la inflorescencia. Las verdaderas hojas son: basales, dispuestas en una roseta floja, pecioladas, ovadas, elípticas, oblanceoladas o espatuladas, indivisas a profundamente pinnatisectas con los segmentos oblongos, de 5 a $30 \mathrm{~cm}$ de largo, de 2 a $7 \mathrm{~cm}$ de ancho, ápice agudo a obtuso, margen entero, base atenuada, venación pinnada, verdes oscuras en el haz, más pálidas en el envés, a veces con zonas más claras en algunas partes de la hoja, glabras. Aparecen en junio o en julio y persisten durante el periodo lluvioso del año.

\section{RESUMEN}

Se describen y se ilustran las hojas verdaderas de Valeriana vaginata HBK., en

Vega RM, Rzedowski J. 1981. Nota aclaratoria sobre las hojas de Valeriana vaginata (Valerianaceae). Boletín de la Sociedad Botánica de México 41: 167-170. 
BOLETIN DE LA SOCIEDAD BOTANICA DE MEXICO No. 41, 1981
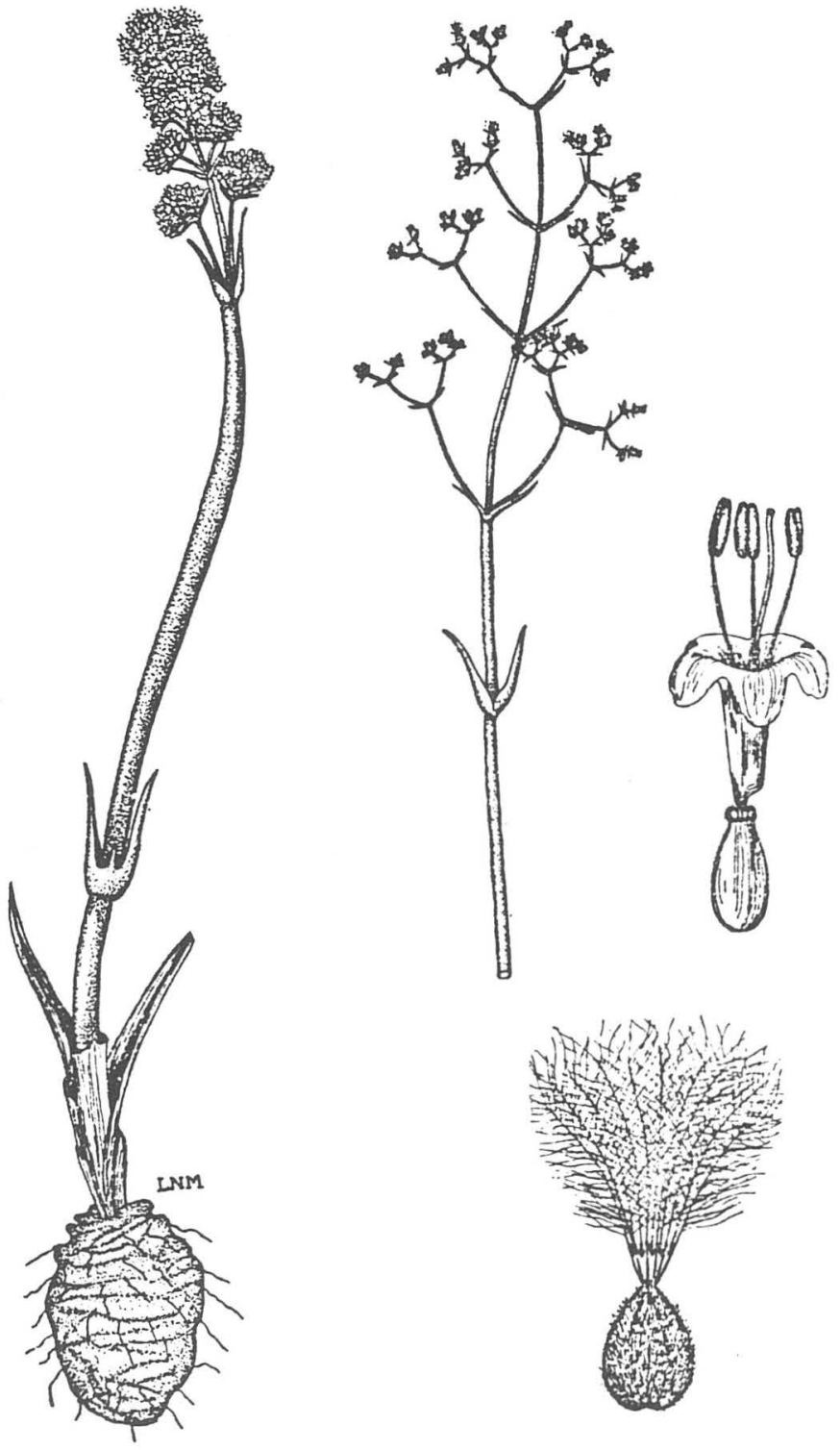

Fig. 1. Valeriana vaginata: planta en flor, $\mathrm{x} \frac{1 / 2}{2}$; inflorescencia abierta, $\mathrm{x} \frac{1 / 2}{2}$; flor, $\mathrm{x}$ 8; aquenio, x 7. (Reproducido de Ann. Mo. Bot. Gard. 38: 453. 1951). 


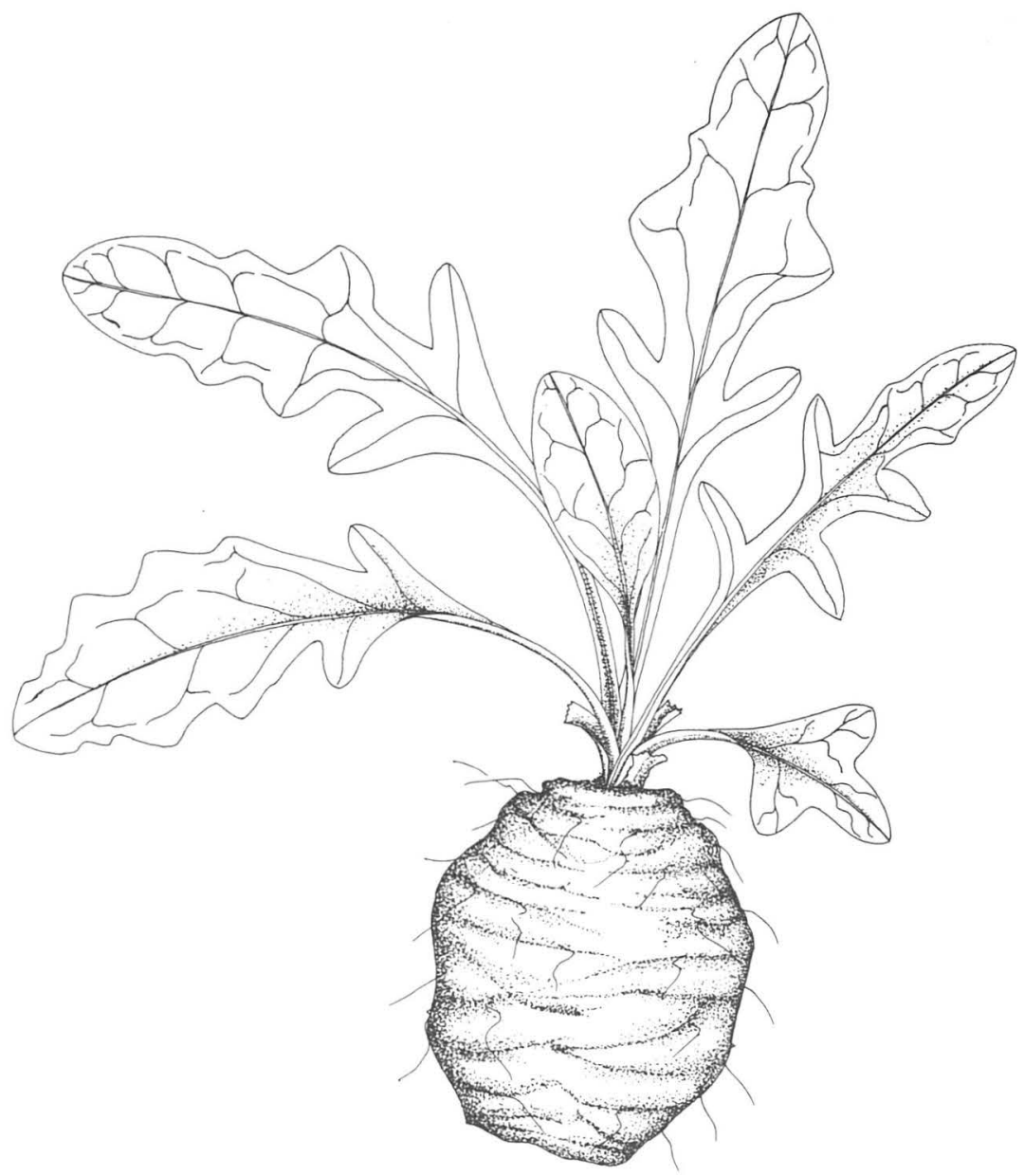

Fig. 2. Valeriana vaginata: planta con hojas, x 1.5. Dibujo de Humberto Sánchez C. 
la cual previamente se interpretaban como hojas las brácteas del escapo y de la inflorescencia.

\section{SUMMARY}

True leaves of Valeriana vaginata HBK. are described and illustrated Previously scape and inflorescence bracts of this plant wwewre interpreted as leaves.

ROSA MA. VEGA

J. RZEDOWSKI

Escuela Nacional de Ciencias Biológicas

Instituto Politécnico Nacional

México 17, D.F.

El segundo autor es becario de la COFAA del I.P.N. 